\title{
La IMPOSIBLe Prisión. Sistema Penitenciario y CARCELARIO EN EL ESTADO SOBERANO DE BOLÍVAR: $1860-1880^{1}$.
}

The Impossible Prison. Penitentiary And Prison System In The Sovereign State Of BOLIVAR: 1860-1880.

Por: José Wilson Márquez Estrada*

*JOSÉ WILSON MÁRQUEZ ESTRADA

Historiador. Magíster en Historiador. Magister en
Historia. Profesor Asistente de la Universidad de Cartagena. Miembro del Grupo de Investigación Frontera, Sociedad y Cultura del Caribe y América Latina (Categoría $y$ A en Colciencias). Al en Colcincias). E-mail: wmarqueze@unicartagena. edu.co / wilsonmarquez99@ yahoo.com.mx.
Artículo tipo 1 de investigación científica y tecnológica según clasificación Colciencias.

${ }_{1}^{1}$ Artículo producto de una investigación sobre Historia del Derecho en el Caribe Colombiano en el Siglo XIX, que adelantó el autor en el grupo de investigación Frontera Sociedad $\mathrm{Y}$ Cultrontera, Sociedad y CulLatina (Categoría A1 en Colciencias), del Programa de Historia de la Facultad de Ciencias Humanas de la Universidad de Cartagena.
Artículo Recibido: Mayo 15 de 2010. Artículo Aprobado: Julio 10 de 2010. Páginas: 198-217

\section{RESUMEN}

El presente artículo trata de las diferentes circunstancias por las que pasó el Estado Soberano de Bolívar con relación al proceso de construcción de un aparato penitenciario y carcelario entre 1860 y 1880, de las diferentes estrategias que se intentaron implementar para saldar el gran obstáculo que se presentó en la construcción de dicho sistema penitenciario, especialmente su problema financiero. Igualmente se describen los diferentes acontecimientos que se vivieron en las distintas provincias que conformaban el Estado en relación con la vida en las cárceles, la situación de los reos, los dispositivos educativos y productivos impulsados dentro de los penales, los conflictos, las situaciones de inseguridad y de hacinamiento, las fórmulas de solución aplicadas, los fracasos y los mecanismos de control y de regulación de la vida carcelaria impulsados para corregir el mal funcionamiento de estas instituciones. Simultáneamente se trata el tema del contexto cultural y político en que se impulsó la reforma carcelaria en Colombia a mediados del siglo XIX y el impacto que ésta tuvo en el Estado Soberano de Bolívar.

Palabras Clave: Cárcel, Prisión, Penitenciaría, Reo, Preso, Justicia.

\section{ABSTRACT}

This article discusses the various circumstances in which the Sovereign State of Bolivar went through in relation to the process of building a prison system and prisons between 1860 and 1880, from the various strategies implemented to attempt to settle it. The major obstacle that was presented in building such penitentiary system was specially its financial problem. It also describes the different events that were experienced in the different provinces that conformed the State in relation with the life in prison, the situation of inmates, educational and productive devices that were driven into the criminal conflicts, insecurity and overcrowding, the formulas and solutions applied, failures and control mechanisms, regulation of prison life to correct the malfunction of these institutions. Simultaneously addresses the issue of cultural and political context that boost prison reform in Colombia in the mid-nineteenth century and the impact it had on the Sovereign State of Bolivar.

Keywords: Jail, prison, penitentiary, inmate, prisoner, justice.

"La deportación desapareció muy rápidamente, el trabajo forzado quedó en general como una pena puramente simbólica de reparación; los mecanismos de escándalo nunca llegaron a ponerse en práctica; la pena del talión desapareció 


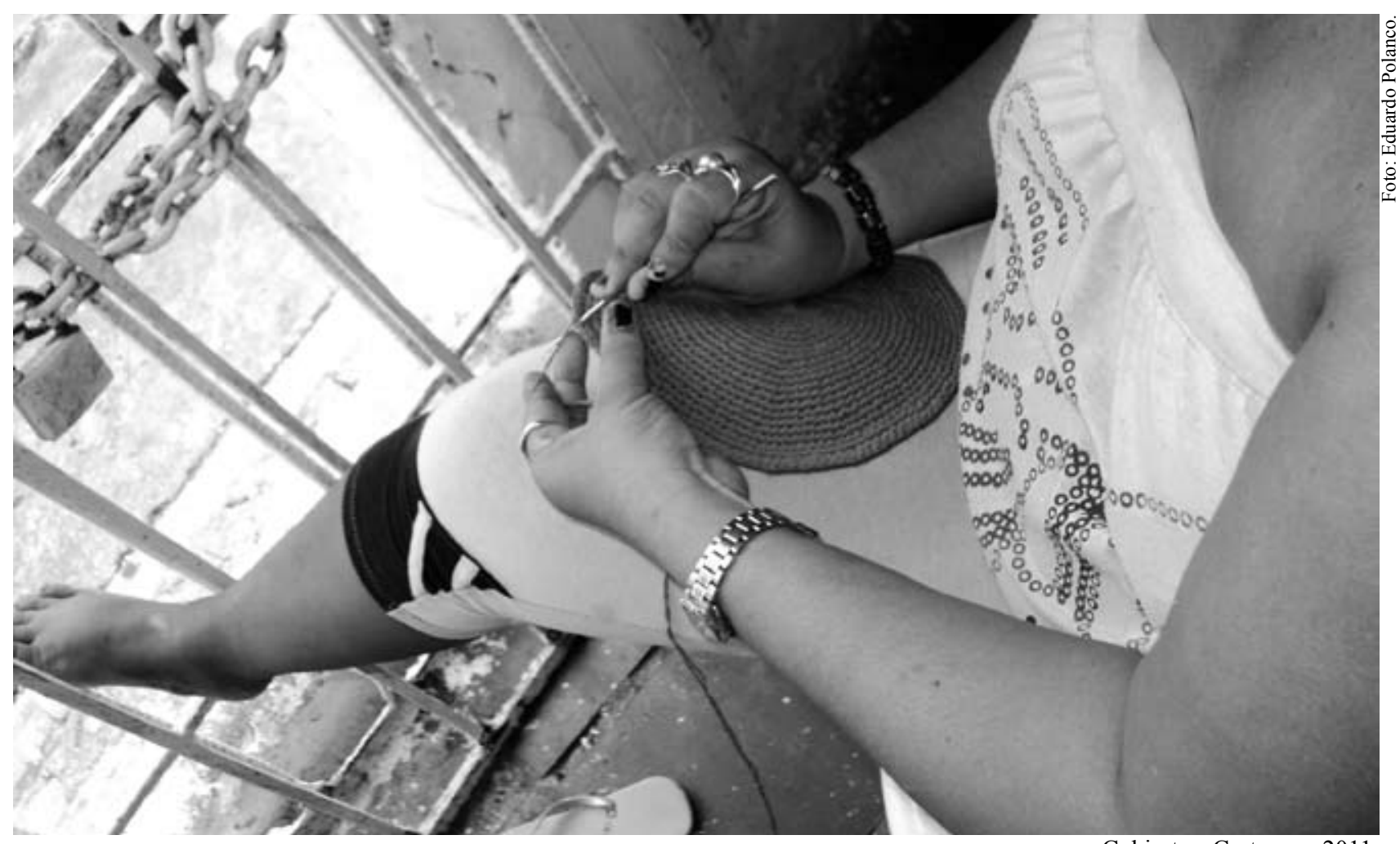

Cubiertas. Cartagena 2011.

con la misma rapidez y fue denunciada como arcaica por una sociedad que creía haberse desarrollado lo suficiente. Estos proyectos de penalidad fueron sustituidos por una pena muy curiosa que apenas había sido mencionada por Beccaria y que Brissot trataba de manera muy marginal: nos referimos al encarcelamiento, la prisión. La prisión no pertenece al proyecto teórico de la reforma de la penalidad del siglo XVIII, surge a comienzos del siglo XIX como una institución, de hecho, casi sin justificación teórica." Michel Foucault (2005).

\section{Introducción}

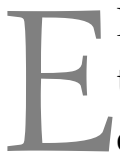

Estado Soberano de Bolívar fue una división administrativa y territorial de los Estados Unidos de Colombia. Creado el 15 de junio de 1857 con el nombre de Estado Federal de Bolívar, a partir de la unión de las provincias neogranadinas de Cartagena, Mompóx y Sabanilla, fue oficialmente reconocido como Estado de la Federación en la constitución nacional de 1858, y finalmente denominado Soberano en la constitución nacional de 1863.

En el nuevo orden federal, a cada Estado le corresponde organizar su aparato judicial y por ende su sistema penitenciario, con todo lo que esto implica, es decir, se debe constituir toda una estructura carcelaria y legislar en este 
sentido, nombrando, administrando, construyendo y financiando los centros de reclusión. Bajo esta perspectiva jurídica y constitucional, cada Estado soberano debía manejar y definir dicha estructura carcelaria independiente del gobierno nacional y con plena autonomía (Naranjo, 2003:296).

En el siglo XIX en Colombia surgió un nuevo sistema judicial de corte republicano caracterizado por el uso generalizado de la cárcel como forma esencial de castigo para el delito. Los legisladores expresaron el interés del gobierno por hacer del castigo un instrumento intimidatorio y ejemplarizante, al más claro estilo colonial, que interiorizara en la población el supremo respeto a la ley y la punición a quien se atreviera a quebrantarla. La cárcel fue una institución que generó desconfianza e inquietudes en los albores del orden republicano y fue bastante criticada por su fragilidad, evidenciando un defecto de la nueva administración de justicia (Villegas, 2006:17).

Con la disolución de la Gran Colombia, en la década de 1830, se produce un gran avance en la organización del sistema penitenciario y carcelario, cuando el nuevo régimen neogranadino expidió una serie de leyes tendientes a regular y organizar los aspectos penales y penitenciarios del ordenamiento jurídico republicano, y en este sentido, se sentaron las bases para construir toda una red carcelaria en el país. La producción de normas por parte del poder legislativo relacionadas con el ordenamiento judicial, implicaba necesariamente definir el asunto de los centros de reclusión; cuestión que tuvo mucha importancia y marcó un verdadero avance en los gobiernos de Santander (López, 1990:323) y de José Ignacio de Márquez. Es así como el presidio urbano surge con el régimen neogranadino, dando origen a la institución carcelaria, diseminada por las distintas regiones y destinada a castigar a los infractores de la ley penal. Este nuevo ordenamiento penitenciario estuvo acompañado por la aparición de un nuevo Código Penal en 1837, que venía a complementar jurídicamente la política criminal que le interesaba impulsar al régimen republicano neogranadino. Es así como quedan fundidos en un solo organismo punitivo los dos sistemas, el penal y el penitenciarioº

${ }^{2}$ Entre el 5 de enero de 1837 y el 17 de abril de 1838 se expidieron una serie de decretos relacionados con los presidios urbanos, que fue complementada con la Ley de 30 de mayo de 1838. En Codificación Nacional de todas las Leyes de Colombia desde el año 1821, hecha conforme a la Ley 13 de 1912 por la Sal de Negocios Generales de Consocios Generales de Consejo de Estado. Tomos VI y VII. Bogotá. Imprent Nacional. 1925.
En Estado republicano creó un sistema penitenciario dependiente del poder ejecutivo y estrechamente conectado con la administración de justicia, que consistía en una serie de distritos penales conformados por centros de reclusión diseñados para atender las necesidades punitivas locales, cantonales y regionales. La local era la cárcel municipal en cada poblado con categoría de distrito municipal; la cárcel del cantón o de circuito que comprendía un 
conjunto de cárceles locales y el presidio que era el organismo de máxima jerarquía (Campuzano, 2000: 98).

El tema más sensible consistía en la consecución de fondos para la construcción de la infraestructura carcelaria. Se contaron con fuentes diversas para satisfacer esta demanda, recursos locales, regionales y nacionales convergieron en este propósito. Fueron los vecinos los que realizaron el esfuerzo económico para construir las cárceles distritales, que reamente terminaron siendo insuficientes, haciéndose necesario recurrir a otros niveles de la administración para saldar estas falencias.

A comienzos de la República la situación carcelaria era verdaderamente crítica y así se mantuvo durante décadas y fueron ingentes los esfuerzos realizados por las autoridades republicanas para transformar este escenario. Esta situación se refleja en el artículo 10 del decreto de Simón Bolívar, de noviembre 24 de 1826 "que ordena que la justicia se administre pronta y cumplidamente"3.

En cuanto a los modelos de presidio implementados en la primera mitad del siglo XIX en Colombia, se puede afirmar que se dieron dos modelos de diferente funcionalidad y connotación punitiva y jurídica: el modelo duro e implacable heredado de la Colonia y el de la institución prevista para el trabajo público, propio de la nueva visión decimonónica disciplinadora de la cárcel moderna (Melossi y Pavarini, 1985: 98). El primero, es decir, el presidio colonialrepublicano perduró hasta mediados del siglo XIX, mientras que el segundo, diseñado para la privación de la libertad en función de la obra pública rigió desde 1837 (Aguilera, 2001:9).

En 1838 el presidente José Ignacio de Márquez (Ocampo, 1993:11), se inclinó por fortalecer el modelo penitenciario heredado de la Colonia y los reglamentó como establecimientos de trabajos forzados con jurisdicción nacional, esos fueron la fortaleza de Cartagena y la fortaleza de Chagres en Panamá4.

Con las reformas de medio siglo el sistema carcelario sufrió una reestructuración que implicó un cambio tanto en la visión como en la ejecución de los proyectos carcelarios en Colombia y que consistía en lo siguiente: a los presidios y establecimientos de reclusión que operaban en las provincias, a la casa de prisión de la capital, a la cárcel de circuito y a la del distrito parroquial, se les sumaría una nueva institución: la penitenciaría. Esta nueva visión estaba contextualizada con la crítica liberal a las condiciones inhumanas que se
3 "... como uno de los principales obstáculos para administrar la justicia criminal sea el mal estado de nuestras cárceles y prisiones de las cabeceras de los cantones, haciéndose los gastos de propios si los hubiere, y si no a costa de los vecinos del cantón interesados, en que no se fuguen los reos $\mathrm{y}$ en que se castiguen los delitos... cuidarán también de que en cada una de las parroquias se asegure una cárcel que construirán los vecinos a su costa si no hubiere otros fondos . " COdificación Nacional. Tomo II. pág. 429.

4 El Fuerte de San Lorenzo localizado a la entrada del Río Chagres, constituye una de las más antiguas fortalezas españolas en América, rodeada por una espesa selva. En 1670 el castillo fue ataca y tomado por fue atacado tomado por Joseph Bradley, siguiendo instrucciones de Enrique Morgan, quien había previsto la destrucción del Fuerte como primera medida para asaltar la vieja ciudad de Panamá. 
${ }^{5}$ Ley del 27 de mayo de 1853 que rompe por completo con el modelo colonial. Codificación Nacional. Tomo XIV. págs. 557-558 y Ley de 6 de junio de 1851 Sobre establecimientos de castigo. Codificación $\mathrm{Na}$ cional. Tomo XV. pág. 725 Decreto del 7 de septiembre de 1853 reglamentario de los establecimientos de castigo. Codificación Nacional. Tomo XV. pág. 725

${ }^{6}$ Constitución Política de los Estados Unidos de Colombia (1863). Artículo $1^{\circ}$ "Los Estados soberanos de Antioquia, Bolívar, Boyacá, Cauca, Cundinamarca Má, Carca, Cundún Santolima, creado respectivamente el 27 de febrero de 1855, 11 de junio de 1856, 13 de mayo de 1857, 15 de junio del mismo año, 12 de abril de 1861 y 3 de septiembre del mismo año, se unen y confederan a perpetuidad consultando su seguridad exterior y recíproco auxilio, y forman una nación libre, soberana e independiente, bajo el nombre de "Estados Unidos de Colombia".

7 Archivo Histórico de Cor-

tagena (AHC), Leyes, Estado

Soberano de Bolívar, Tomo $\mathrm{N}^{\circ}$ 18, Año 1872, Folio 54 y ss. y Gaceta de Bolívar, Trimestre LXIII, $\mathrm{N}^{\circ} 705 \mathrm{Ex}-$ traordinaria del sábado 20 de agosto de 1870 pág. 320 a 327. N 709 , Extraordinaria de lunes 5 de septiembre ria de 1870 , pag. 353 a 359 ; de 1870 , pág. 353 a 359 ; $\mathrm{N}^{\circ} 711$ Extraordinaria de sábado 17 de septiembre de 1870 , pág. 369 a $375 ; \mathrm{N}^{\circ}$ 713. Gaceta de Bolívar, de Martes 27 de Septiembre de 1870, págs. 393 a 396

8 AHC. Tomo de Leyes N ${ }^{\circ}$ 18, del Estado Soberano de Bolívar. vivía en las cárceles y apuntaba a un nuevo sistema carcelario más seguro y humano, que consistía en un tratamiento institucional de los reclusos. Es así como en 1853 desaparece este tipo de presidio, el de los trabajos forzados, heredado de la Colonia, para posibilitar el surgimiento de una nueva institución: el presidio de trabajo en obras públicas. Suprimir los trabajos forzados significó realmente un mejor trato para el reo, entonces el vetusto presidio de origen colonial dio paso al presidio de estilo republicano, que funcionaba como un centro de reclusión dentro de la misma provincia donde los detenidos pagaban su pena trabajando ${ }^{5}$. Este modelo de prisión estaba de alguna manera influenciado por el modelo de prisión-fabrica norteamericano y europeo, donde el trabajo estuvo dirigido al beneficio del sistema productivo particular, a diferencia del nuestro donde se insistió más en los trabajos en obras públicas, costumbre punitiva de fuerte tradición hispana (Tomás y Valiente, 1992: 355).

\section{Sistema penitenciario y carcelario del Estado Soberano de Bolívar.}

Con el nuevo orden federal que trajo consigo la Constitución de Rionegro ${ }^{6}$, cada uno de los Estados que conformaba la unión se dio un nuevo ordenamiento jurídico en materia penal, fundamentado en la experiencia republicana anterior en esa materia (Puerta, 2009: 123). En consecuencia, el Estado Soberano de Bolívar construyó su propio código penal bajo la influencia del Código Penal de 1837 cuyo proyecto y definitivo texto fue publicado en la prensa oficial ${ }^{7}$, los cuales fueron anexados a la ley que definió su sanción en $1872^{8}$.

La necesidad de organizar un sistema penitenciario en el Estado Soberano de Bolívar con una infraestructura básica carcelaria eficiente, que le permitiera el tratamiento de los delincuentes en los términos planteados por el liberalismo, fue una constante durante todo este período. La transformación del sistema judicial y penitenciario hacia uno más civilizado, contenía implícito el cuestionamiento a su eficiencia y sobre todo la necesidad de construir una infraestructura carcelaria mínima que garantizara la seguridad y la eficacia de dicha institución. Esto implicaba por parte de las autoridades gubernamentales activar todo un dispositivo de construcción, mantenimiento, arriendo de locales, reglamento de cárceles, distribución de recursos, condiciones e higiene, instrucción y trabajo. La realidad, con relación a este tema, heredada del pasado, era crítica. El sistema carcelario era deficiente, el Estado no contaba con instalaciones propias ni acondicionadas para este fin. Las pocas cárceles existentes eran inseguras y se facilitaba la fuga de los presos. No existía una 
política administrativa clara y, por ejemplo, con relación a la manutención de los presos, no había un programa de asistencia directa, sino que los penados recibían una ración diaria en dinero para su sustento. A pesar que la ley ordenaba entregar una dotación diaria de ropa, esto no se cumplía y los presos exhibían una figura harapienta. Para asegurar la seguridad del reo se recurría a las formas tradicionales del cepo y la barra, en detrimento de su dignidad e integridad física. Para cambiar estas denigrantes circunstancias de reclusión, el Estado emitió una serie de leyes entre las que se encuentra la Ley del 31 de diciembre de 1862, que disponía la construcción de cárceles de provincia en donde no las había y se proveyera de recursos para su construcción.

Igualmente, por medio de esta disposición legal, se prohibió el uso de la barra y del cepo, ordenaba construir dos calabozos seguros y ventilados destinados uno para hombres y otro para mujeres ${ }^{9}$. Otra ley, la Ley del 2 de enero de 1863, posibilitó que los reos condenados a penas de reclusión y prisión pudieran ser destinados a trabajos públicos, mientras se organizaran las casas de castigo, resaltando que esta disposición no aplicaba para aquellos reos condenados a reclusión con aislamiento ${ }^{10}$. La Ley del 19 de octubre de 1869 , permitía al Estado y su poder ejecutivo celebrar convenios con Estados vecinos para solicitar la entrega de presos ${ }^{11}$. La Ley del 7 de diciembre de 1868 instauró la figura de la "fianza carcelaria" o "fiador de cárcel segura", aplicable únicamente para delitos de menor gravedad, la fianza era respaldada por un ciudadano, vecino del distrito, y de buenas condiciones económicas, quien se comprometía por medio de acta a presentar a su fiado cuantas veces se le requiriera so pena de pagar una multa. Otra ley, relacionada con los negocios criminales, ordenaba que los presos enfermos, con previo aviso al ministerio público, debieran ser trasladados a un centro hospitalario bajo custodia.

Para el año 1870 la situación carcelaria era crítica y se agravaba por la falta de edificios óptimos para tal fin y la fuga de presos, era el pan de cada día. Con relación a esta situación, el gobernador de la provincia de Barranquilla expresaba que "solamente hace falta en esta provincia para que fuera infalible el castigo de los criminales, que hubiera una cárcel con seguridad, capacidad y buenas condiciones higiénicas... Pues contando estos con la capacidad de la fuga, poco les importa reincidir, i su vida viene a ser una cadena sin fin de delitos, fugas, prisiones i juicios interminables. iAsí no se puede vivir!..."12.

En el año 1871, en la provincia de Lorica, durante una visita que realizó el Presidente del Estado y su secretario general a la cárcel de la municipalidad, se

PalObra No. 11. Septiembre de 2009 - Agosto de 2010
9 AHC. Leyes, Libro de la Asamblea Legislativa del Estado Soberano de Bolívar, año 1862 , tomo $\mathrm{N}^{\circ} 5$ folio 77 .

${ }_{10}$ AHC. Leyes, Libro de la Asamblea Legislativa del Estado Soberano de Bolívar, año 1862 , tomo $\mathrm{N}^{\circ} 5$, folio 83

${ }^{11}$ AHC. Leyes, Estado Soberano de Bolívar, tomo $\mathrm{N}^{\circ} 14$, año 1869, folio 40-41.

12 AHC Gaceta de Bolí var, número 707 , trimestre LXIII, domingo 28 de agosto de 1870 , pág. 337. 


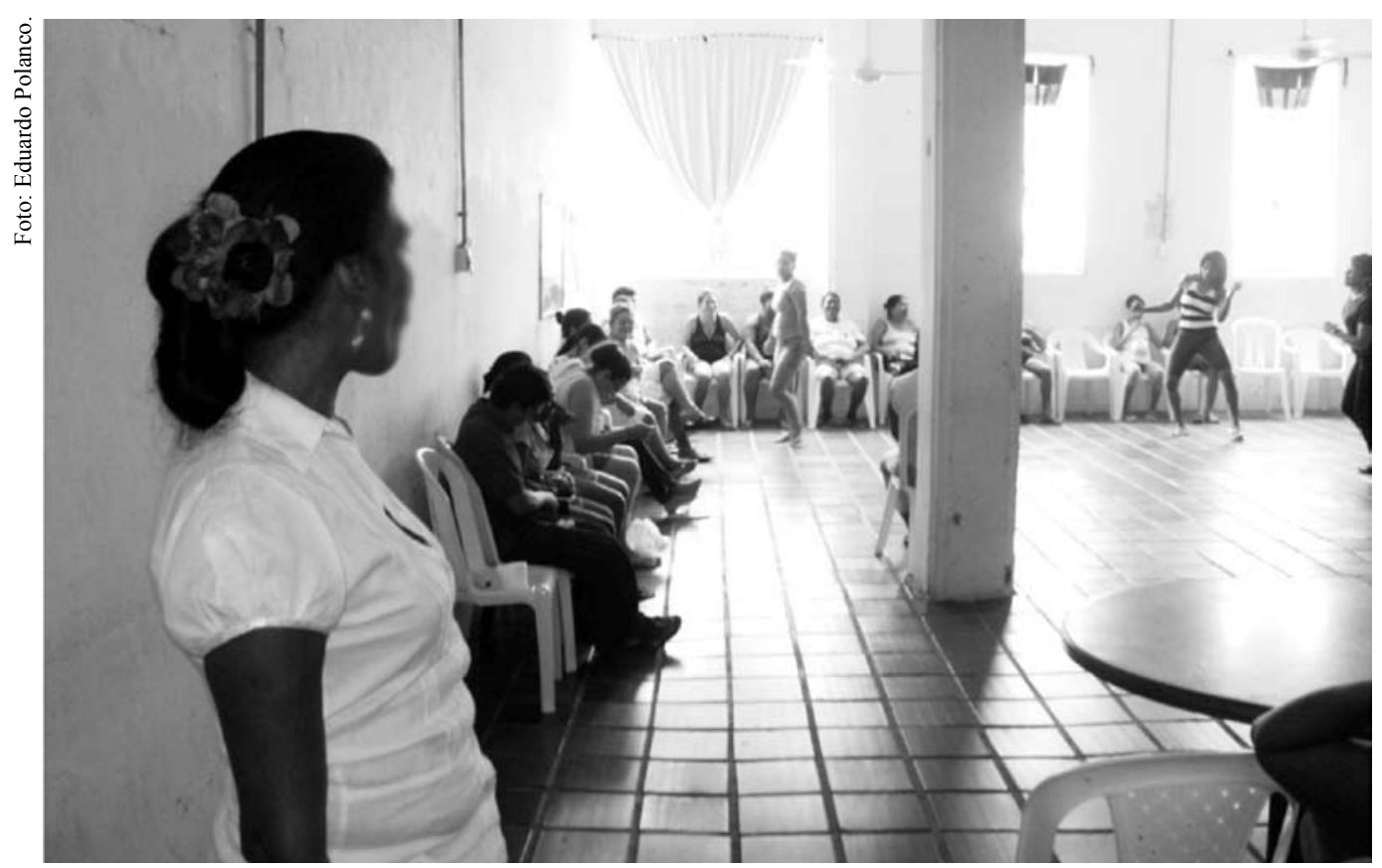

Actividades varias (Carcel de Mujeres, San Diego) 2011.

toparon con el hecho que la edificación constaba de una sola pieza, construida con cañas, totalmente insegura, y lo más grave, ni siquiera era propia sino arrendada por el municipio. La única seguridad que prometía dicha cárcel consistía en que los reos se encadenaran en la barra que allí existía. En su informe sobre esta visita los funcionarios anotaron que "todos están colocados en la barra de un pie. No hai libro de entradas y salidas, ni relación de presos, ni puede haberla por que el alcaide no sabe leer ni escribir"13.

En el año de 1871, en su informe anual el gobernador de la provincia de Chinú, manifestaba al presidente del Estado:

Los sindicados que hay en la cárcel de esta capital, carecen de medios de subsistencia, i como la autoridad judicial no los declara pobres de solemnidad $i$ con derecho a ser racionados por el estado sino cuando son llamados a juicio, se han presentado frecuentes casos en que esos individuos se han visto expuestos a morir de hambre, si la caridad no hubiese acudido a su socorro. También es exigua la ración de diez centavos de los acusados pobres. La mitad de lo que comúnmente se da como ración diaria ${ }^{14}$. 
en la parte de abajo, estaría destinada para otra clase de penas y la tercera ubicada también en la parte de abajo, estaría destinada para el taller para detenidos o sindicados. Se ordenó que no debieran mezclarse los condenados y los sindicados. Igualmente esta ley disponía que los arrestos correccionales no debieran cumplirse en la prisión del Estado sino en la cárcel del distrito. En esta ley igualmente se establecía que la enseñanza, aprender a leer y a escribir, y las artes y oficios eran de carácter obligatorio para los reos. Esta política reeducativa buscaba de alguna manera la reinserción del individuo que había delinquido, que había roto el pacto social, a la vida en sociedad y a su condición de ciudadano, política que estaba a tono con el ideario liberal de la época.

Se buscó reglamentar la vida carcelaria por parte del Estado, tanto a nivel de provincia como a nivel de distrito, en esta reglamentación se estipulaba todo lo concerniente a la construcción, adecuación y amoblamiento del edifico carcelario, así como todo lo concerniente con la vida del penal; por ejemplo el reglamento de la cárcel del año 1875 de la provincia de Corozal estipulaba que "a ningún detenido o preso se le permitirá llevar a la cárcel muebles u otros objetos destinados a la comodidad de la vida. Cuando no los haya en el establecimiento se les dejará apenas conducir una cama, un asiento, vasija, aljofaina, vaso, mesa, útiles de escritorio i libros"15. El gobernador de dicha provincia en su informe anual al Ciudadano Presidente decía en este mismo año -refiriendose a la situación carcelaria- que "de ordinario nuestras cárceles y nuestras casas de castigo son, como dijo un eminente escritor colombiano: 'establecimientos en que se ejerce una venganza estúpida i más criminal que el mismo crimen'. En nuestros establecimientos penales no se corrije o castiga, sino que se encarcela, se martiriza i se condena al hombre a que se corrompa."16

Con relación a la crueldad de la pena carcelaria y a las condiciones infrahumanas que padecían los reos en los centros penitenciarios, el gobernador de la provincia de Cartagena, Ignacio G. Guerra, en 1878, expresaba lo siguiente:

Los condenados a sufrir la pena de aislamiento, continúan en un departamento enteramente independiente y comunicado, $i$ sobre lo cual me voy a permitir hacer algunas indicaciones: Abolida la bárbara pena de muerte preciso e indispensable fue que para los delitos atroces se impusiera una pena severa i que no tuviera los inconvenientes que aquella, i nuestros legisladores, siguiendo el ejemplo de naciones más adelantadas en civilización que la nuestra, adoptaron la de aislamiento, pena menos

${ }^{15}$ AHC. Diario de Bolívar año XVIII, $\mathrm{N}^{\circ} 1995$, julio 30 de 1875 , pág. 684. ${ }^{16}$ AHC.' Diario de Bolívar, año XVIII, No 1201 , agosto

PalObra No. 11. Septiembre de 2009 - Agosto de 2010 
17 AHC. Diario de Bolívar, año XXI, $\mathrm{N}^{\circ} 1945$ agosto 14 de 1878, pág. 1346.

${ }^{18}$ Ibíd.

19 AHC. Diario de Bolívar, año XXI, $\mathrm{N}^{\circ} 2094,14$ de marzo de 1879 , pág. 147.

20 AHC. Diario de Bolívar. año XXI, N $\mathrm{N}^{\circ} 2141,14$ de junio de 1879 , pág. 334. bárbara pero más cruel que la muerte. Condenar a un individuo por tres, cuatro i hasta por cinco años a la inacción i mudez, a la privación del agua para baños jenerales, elemento indispensable para todo ser viviente, es condenarlo a una muerte lenta, es condenarlo a la desesperación, cuyo resultado con mucha frecuencia, es la enajenación mental ${ }^{17}$.

Bajo esta perspectiva de análisis se propuso al ejecutivo que se transformara la pena de aislamiento y que a pesar que el individuo estuviera aislado, se le obligara a trabajar, leer libros morales y científicos y hacer uso del agua para baños generales en determinados días. Esto lo que buscaba era no condenar al total abandono al reo aislado e intentar de alguna manera recuperarlo para la sociedad. El dato estadístico del número de presos condenados a la pena de aislamiento era alto, por ejemplo en el año de 1878 en la provincia de Cartagena de 63 presos, 14 estaban condenados a la pena de aislamiento ${ }^{18}$.

En el año de 1879 en informe al Ciudadano Presidente, el gobernador de la provincia de Cartagena, se quejaba que en la cárcel de la provincia de Cartagena los presos vivían mezclados hombres con mujeres y reos sindicados con reos condenados. Igualmente los aislados se confundían con los detenidos. Simultáneamente señalaba que la seguridad era aceptable pero las condiciones eran malas. Se quejaba que a pesar que la ley ordenaba dar una dotación de ropa a los internos cada seis meses, esto no se cumplía y las condiciones de vestuario de los reos eran notoriamente precarias; esto evidencia que una cosa son las disposiciones legales y otra muy diferente su cumplimiento efectivo. El procurador también hizo referencia al hecho de que en años anteriores se había establecido una escuelita dentro del penal que había producido muy buenos resultados pero que por circunstancias que él no se explica había desaparecido. Finalmente termina su informe diciendo que en el momento había en dicho establecimiento carcelario 64 reos rematados, es decir, condenados ${ }^{19}$. En ese mismo año de 1879 se suprimieron las raciones en dinero que se le entregaban a los reos, sistema que se cambio por el nuevo régimen de rancho que consistía en la asistencia directa en especie alimenticia para los presos, evitándose así la circulación de dinero dentro del penal ${ }^{20}$. En el mismo año de 1879, en su informe anual el gobernador de Sincelejo al Presidente del Estado, insistía en la necesidad urgente de construir una cárcel en esa provincia y lo decía en los siguientes términos:

No ha mucho se ha palpado la suma necesidad que hai de un edificio seguro, para cárcel provincial, pues habiendo aunque fuera un calabozo, de cal $i$ 
ladrillos capaz, allí estaría todo delincuente que se le hubiera privado de su libertad, salvándolo así de la terrible prisión de cepo i barra, que no puede ser mas vejatoria para los ciudadanos que tienen la desgracia de sufrirla; pero de rigor hai que aceptarla, porque peor sería la impunidad de los delitos... De la cárcel de aquí se fugaron en la noche del 26 de Abril doce criminales entre los cuales habían algunos que tenían tres años de estar en prisión de barra; otros, dos; i otros, uno. Debemos calcular cual sería la desesperación de aquellos desgraciados que jemían en aquella prisión agobiados doblemente por sus sufrimientos propios i los de sus familia ${ }^{21}$.

Lo que más lamentaba el gobernador en este informe era que la cárcel estaba construida en madera y palma, lo que la hacía bastante vulnerable en términos de seguridad. Esta circunstancia se agravaba con el hecho que en ninguno de los otros distritos de la provincia de Sincelejo no había ninguna clase de cárceles, que solo en Tolú existía una, que servía de paso a los reos rematados que iban a cumplir su condena a la cárcel del Estado que quedaba en la capital ${ }^{22}$.

Como se puede observar la situación carcelaria era bastante grave en esta época, es decir, a finales de la década del setenta, verdadera problemática de inseguridad carcelaria y de ausencia casi absoluta de una infraestructura penitenciaria básica en todo el Estado. Situación que se agravaba por las circunstancias que vivían los presos rematados en las cárceles y la inseguridad que planteaban los reos prófugos a las autoridades, deambulando tranquilos por los campos y por las calles de los poblados. Con relación a este último tema, el Código de Procedimiento Criminal disponía que los juzgados de provincia y el tribunal debían remitir una lista de reos prófugos o ausentes al poder ejecutivo que disponía de esta información para ordenar la captura de estas personas, para esto se diseñó una lista que se publicó en el diario oficial y se le enviaba a todas las autoridades del Estado. En el año de 1870 el señor gobernador de la provincia de El Carmen, se alarmaba por la situación de los reos prófugos y el peligro que representaban para la sociedad y de cómo este hecho era una circunstancia constante y grave: "no hai en la cárcel de esta capital sufriendo su pena ningún rematado. Los que han sido juzgados i penados, están sufriéndola en la cárcel de la capital del Estado, de donde se han fugado la mayor parte de ellos"23. El número de reos prófugos para el año de 1875 era verdaderamente alarmante, dato que se puede constatar en la prensa oficial de la época donde se publicó una lista de 723 reos prófugos con causa criminal abierta en el tribunal y en los juzgados de provincia del Estado, la mayoría

PalObra No. 11. Septiembre de 2009 - Agosto de 2010
${ }^{21}$ AHC. Diario de Bolívar, año XXII, $\mathrm{N}^{\circ} 2181,16$ de agosto de 1879 , pág. 494. 22 Ibíd.

${ }^{23}$ AHC. Gaceta de Bolívar, N ${ }^{\circ}$ 704, trimestre LXXIII, 14 de agosto de 1870. pág. 314 
condenados por los delitos de mayor ocurrencia en el Estado: hurto, heridas, asesinato, homicidio, maltrato, fuga y en menor proporción rapto y estupro, resistencia con armas a la autoridad, incendio y robo ${ }^{24}$.

\section{La problemática de la administración carcelaria.}

La construcción y sostenimiento de un sistema penitenciario y carcelario era una carga financiera bastante fuerte para el Estado Soberano de Bolívar y este permanentemente evitaba comprometerse de fondo con esta obligación. Es decir, el Estado ante la falta de una buena capacidad financiera que le permitiera atender la crisis de la situación carcelaria intentaba de alguna manera superar la crisis comprometiendo con esta obligación a los otros entes administrativos territoriales. En su informe anual al Presidente del Estado, el gobernador de la provincia de Barranquilla decía "el distrito no puede ni quiere componer la cárcel, porque se cree que el Estado, que es el que se sirve de ella, es el que debe hacer el gasto, i el estado tal vez habría construido una cárcel hace tiempo, sino tuviera ahí la cárcel del distrito prestando sus servicios, sea como fuere; aunque los presos se mueran, inutilicen o enfermen por estar hacinados en calabozos estrechos, húmedos y sin ventilación."25

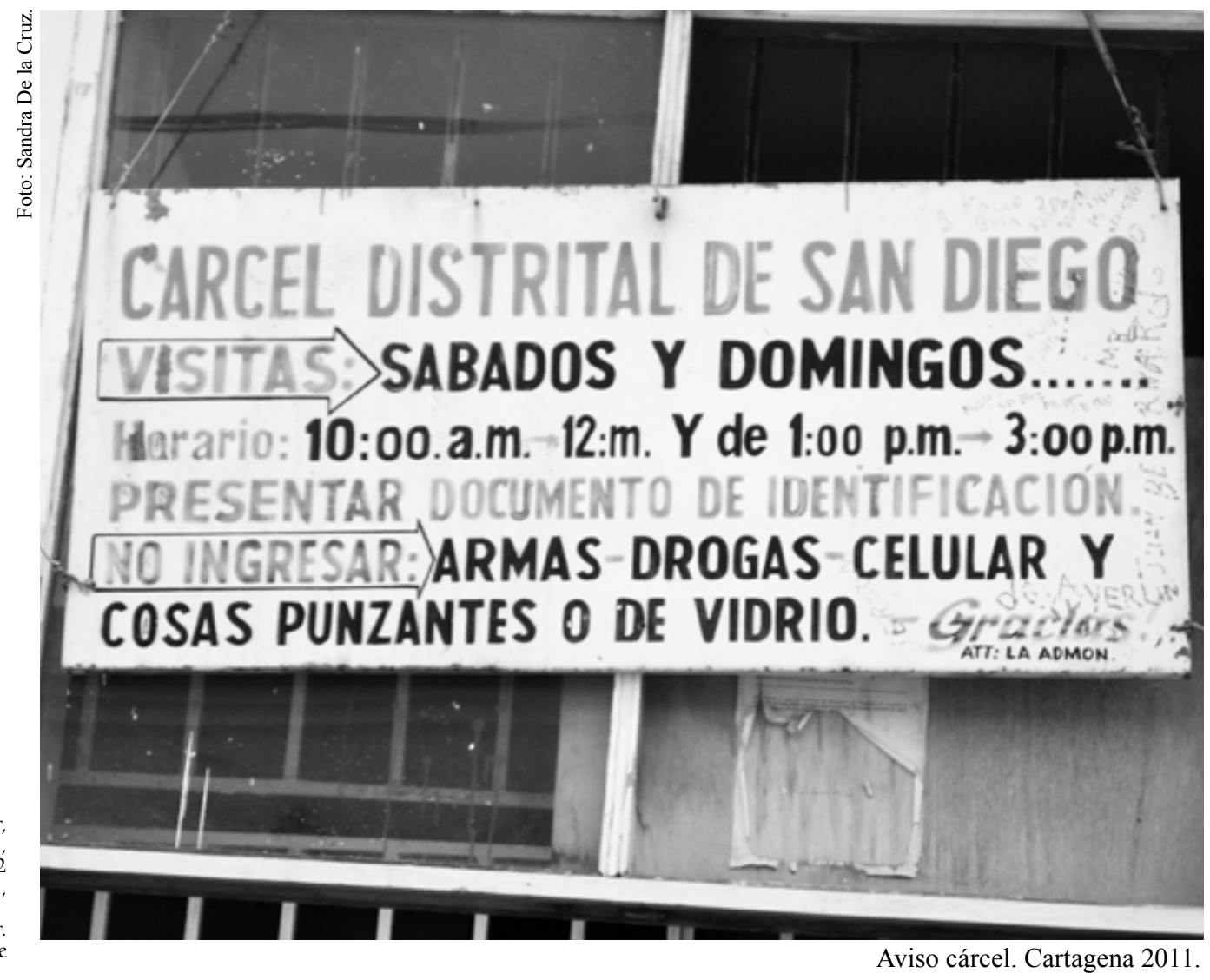


Una de las conductas recurrentes del Estado de Bolívar con relación a la asistencia carcelaria en el aspecto locativo, era que en las provincias donde no poseía establecimientos carcelarios propios suplían la necesidad mediante alquileres anuales de edificaciones adecuadas para tal objeto, de propiedad de individuos particulares o de los distritos. Eran frecuentes las quejas por la falta de pago del canon de arrendamiento por parte del Estado que demoraba meses y años. Si las edificaciones pertenecían a los distritos, el Estado descargaba en ellos los gastos de reparación y mantenimiento. En su informe anual un gobernador de provincia se quejaba de esta situación y expresaba que:

El local en que existe la Cárcel de la Provincia es de propiedad del Distrito i el estado viene haciendo su uso gratuito de él desde el año 1862 en que se construyó. Los presos de la provincia muchas veces lo han roto; el uso descompone las puertas y cerraduras siendo siempre del tesoro del Distrito que se hacen las reparaciones; $i$ esto da lugar en que a veces no tengan las seguridades debidas... la justicia $i$ equidad por una parte se opone a que por mi se compela al Distrito a que atienda de una manera regular a la erogación de estos gastos. I esto hace solicitar que el estado le pague al Distrito el arrendamiento del local, como lo han hecho en varias partes; i que le impongan a la vez la obligación $i$ hacer los reparos i mejoras que sean necesarias ${ }^{26}$.

El conjunto de instituciones carcelarias de las provincias y de los distritos formaban la estructura del sistema penitenciario en el Estado Soberano de Bolívar. Carecían de una eficaz organización física para atender la demanda de resocialización penitenciaria, además debían albergar únicamente a individuos condenados a pena de cárcel de no más de un año, por lo que los delincuentes condenados a penas mayores eran trasladados a la penitenciaría del Estado o Casa de Prisión y Reclusión de Cartagena para iniciar el proceso disciplinario y educativo que pretendía hacerlo útil a la sociedad (Mantovani, 1998:172). En las cárceles de provincia encerraban a los individuos sindicados de los delitos cometidos en los distritos que hacían parte de dicha provincia y eran remitidos allí desde las cárceles distritales. Las cárceles distritales eran las de menor calidad de alojamiento, lo que significaba que eran poco adecuadas para cumplir con la pena privativa de la libertad, por ser lugares oscuros, húmedos, estrechos y poco ventilados. El gobernador de la provincia de Barranquilla expresaba que "se ejerce en ellos una venganza estúpida i más criminal que el mismo crimen... esos establecimientos son de pura detención, i la justicia quiere que se guarde en ellos a los presos sin otro castigo que la falta de 
libertad, mientras que corrige prudentemente a los unos i averigua si son inocentes o verdaderos criminales los otros..." 27 .

Ante esta dramática situación el Estado Soberano de Bolívar, buscando desesperadamente recursos económicos para intentar subsanar el problema financiero, se inventó la fórmula de la concesión de tierras baldías. Es así como la provincia de Mompox, mediante la Ley $7^{\circ}$ de 1877 , recibió del Estado, para la reparación de la casa que funcionaba como cárcel de la provincia, los títulos de 11.000 hectáreas de tierras baldías. Pero este remedio resultó siendo insuficiente porque la tramitología hacia casi imposible convertir estos recursos en dinero en efectivo para iniciar las reparaciones o las construcciones necesarias. Haciendo referencia a esta apremiante situación, el gobernador de dicha provincia Martín Salcedo, en su informe al Ciudadano Presidente, manifestaba lo siguiente:

... aún cuando las condiciones personales de los miembros de la junta encargada de la refacción... sea una garantía de la realización satisfactoria de este convenio, no ha podido principiar los trabajos, porque siendo el producto de la venta de los títulos el recurso principal, a pesar de haberlos reclamado, permanecen en Bogotá a donde fueron enviados por la Junta Patriótica para su conversión a otros de más fácil venta ${ }^{28}$.

Ante estas dificultades las provincias tenían dos opciones; esperar que el tesoro del Estado destinara en algún momento los fondos necesarios para ejecutar los gastos que demandaban los establecimientos carcelarios, o que los concejos municipales junto con los habitantes asumieran los gastos referentes a este tema. El gobernador de la provincia de Sincelejo en su informe anual al Presidente del Estado, se pronuncia sobre esta situación:

La cárcel del Distrito capital que sirve a la provincia desde años mui remotos, estaba ya en estado de inutilidad, i fue preciso que la municipalidad, no obstante la escasez de sus recursos, la refaccionara en el año próximo pasado, cosa que se llevó a cabo no solo con aquellos, sino con la cooperación de algunos vecinos labradores que patrióticamente se prestaron a contribuir con algunos materiales ${ }^{29}$.

${ }^{27}$ AHC. Diario de Bolívar. 12 de agosto de 1876. No. 1503. pág. 508.

28 AHC. Diario de Bolívar. Cartagena, 23 de julio de 1878. No. 1926. pág 1266 .

29 AHC. Gaceta de Bolívar. Cartagena, 29 de julio de 1878. No. 1931. pág. 1291.
Una buena construcción garantizaba la seguridad en el penal, lo que implicaba que el gasto en materiales de construcción era básico dentro de lo presupuestado, siendo complementado con una serie de dispositivos técnicofísicos de seguridad como el conjunto formado por los cepos, grillos, cadenas, 
barras, etc.; cuyo uso generalizado se debía a la inseguridad de estas casas. Entonces era obvio que la seguridad de estas cárceles dependía ante todo de una buena estructura física. Un gobernador de la época se quejaba al respecto:

La provincia de Barranquilla posee una cárcel construida con paredes de ladrillo, mezcla i techo de azotea - con cinco divisiones. En el Distrito de Soledad; una cárcel de la misma construcción... tiene una sala i rejas de madera. En el Distrito de Malambo; hai una cárcel pequeña de techo pajizo i paredes de horcones, embutidas con barro i empañotadas i tienen cuarto $i$ una sala, i esta en buen estado. Solamente le falta blanquearla i ponerle puertas para que llene su objeto. Sabana Grande; cárcel de propiedad particular, i estaba en mui mal estado, i sin seguridad ninguna... en el Distrito de Santo Tomas; una cárcel de paredes de horcones embutidas con barro i cascoteadas con mezcla i ladrillo i blanqueadas i con techo pajizo de palma de sará o palmiche; i tiene tres piezas una sala i dos cuartos. En el Distrito de Galapa; una cárcel en mui mal estado que necesita ser reconstruida para que llene su objeto. En el Distrito de Tubará; una cárcel bastante capaz de techo pajizo i paredes embutidas i empañotadas... sólo le falta blanquearla $i$ componerle el suelo para que este útil $i$ adecuada para su objeto ${ }^{30}$.

\section{Una nueva visión de la función punitiva del Estado: Regulación y disciplina.}

Con relación a la Ley del 2 de diciembre de 1869 que otorgó atribuciones a los gobernadores para redactar los reglamentos de las cárceles provinciales. En circular el Secretario General del Estado solicitaba a todos los gobernadores:

dar cumplimiento a la última parte de la disposición que he copiado, espero que usted en todo el mes de marzo próximo, me envíe copia de dichos reglamentos, i caso de que por cualquier motivo no se haya expedido, o no pudiera conocerse el reglamento, Ud. se servirá expedirlo i enviar la copia en dicho mes, a fin de que sean publicados todos en una misma gaceta... Un libro foliado, firmado i rubricado por el Gobernador, divido en cuatro partes; la primera división destinada a la alta i baja de los individuos condenados a la pena de prisión, en cuyas páginas deberán formarse tantas columnas cuantas son necesarias para expresar el nombre $i$ apellido, el día $i$ la hora de la entrada, el motivo de esta, i la autoridad que lo disponga, las cuales formaran las altas; $i$ al frente se verificarán las bajas, expresando el día i la hora de la salida, la autoridad que lo disponga i la cita de la

30 AHC Gaceta de Bolívar. 28 de agosto de 1870 . No. 707. pág. 337 . 
partida de entrada; la segunda división se destinará a la altas i bajas de los procesados o criminales i en la misma forma; la tercera división servirá para hacer constar la salida i la entrada de los arrestados; i la cuarta para hacer expresar todo lo relativo a la salida de la enfermería... ${ }^{31}$.

El efecto inmediato de esta disposición legal es la redacción y publicación de los reglamentos de todas las cárceles del Estado de Bolívar, los cuales estatuyen que el director de la cárcel es el alcaide, nombrado por el gobernador de la provincia y por el período de un año. Tenía como funciones, entre otras, la de cuidar el uso y conservación del edificio, informando de las reparaciones que debían realizarse. Tenía bajo su responsabilidad la disciplina y buen funcionamiento de la cárcel, además de llevar un registro de todo lo que tenía que ver con el penal. Los gobernadores, alcaldes o jueces tenían obligación de visitar las cárceles cada 15 días. El documento central de revisión en la visita era el libro de Registro donde se asentaba todo lo relacionado con la vida del penal, complementada por las informaciones que se recogían acerca de la vida dentro del penal, tales como desordenes, fugas y todo tipo de irregularidades. Estos funcionarios interrogaban a los presos acerca del trato que les brindaban, y sobre la demora o prontitud del juicio a que serían o dado el caso fueron expuestos. En los informes sobre estas visitas se evidencia el estado de abandono de estos centros de reclusión. A continuación se señala lo que dice el Ciudadano Presidente con relación a este tema en una visita a la cárcel del distrito de Sabanalarga:

no hai mobiliario de ninguna especie ni hai otro archivo que dos pequeños legajos de boletas de encarcelación i excarcelación... notándose que no hai boleta con relación al preso Nicolás Barrios i que la dada por el juez de la provincia para detener a Rufino Polo no expresa el motivo de la prisión. No hai libro de entradas ni de salidas de presos, ni relación de los existentes. El Alcaide informó que no sabe leer ni escribir. No hai libros de visita informando el Alcaide que ninguna se ha pasado durante el año por ninguna autoridad ${ }^{32}$.

31 AHC. Gaceta de Bolívar. Domingo 28 de abril de 1878. No. 809. pág. 73.

32 AHC. Registro de Bolívar, 23 de julio de 1871 . No. 756. pág. 117. 
propio por las autoridades políticas del Estado Soberano de Bolívar, donde se resaltaban ideas como esta:

consignada en nuestra legislación la doctrina cristiana de la redención del criminal es ante todo punto indispensable la creación del instrumento que la filosofía señala como medio material competente para realizar tan grande objeto. La expresión lógica de aquella doctrina es la penitenciaría, esa especie de puente colocado entre el bien i el mal para la rehabilitación del criminal, en donde la sinceridad de la justicia se enlaza a la fraternidad... toca a vosotros la alta prez de dar en tierra con esa reminiscencias andrajosa de la barbarie, que amenaza nuestro honor nacional,... se quiere solo la creación de un establecimiento que tiene su autoridad en la conciencia de la sociedad, como tiene virtualmente su existencia en la lei, su legitimidad en el derecho, su garantía en la sanción de un siglo; i de que con urgencia necesita por consiguiente el gobierno para la salud del estado ${ }^{33}$.

En este orden de ideas, toda esta filosofía de la prisión estaba en correspondencia con la acentuación del individualismo, con las ideas de libertad e igualdad predicadas durante el periodo del federal y que posibilitaron acabar con la prevalencia de la pena de muerte como castigo ejemplar a los delitos graves; imponiéndose así el proyecto penal de penitenciaría, adoptado de las legislaciones foráneas. En esta perspectiva, se institucionaliza el modelo penitenciario de Filadelfia, adoptado definitivamente en el período del liberalismo del tercer cuarto del siglo XIX en Colombia. Para el caso de la provincia de Cartagena, el tratamiento resocializante más extremo que se implementó en la Casa de Prisión y Reclusión, consistió básicamente en la pena de aislamiento, que no obstante ser un mecanismo punitivo más blando que los trabajos forzados, recibió las más fuertes críticas en su momento. La pena de aislamiento que correspondía a los condenados por delitos graves o aquellos que su conducta dentro del penal era peligrosa para la convivencia, era objeto de críticas debido a la rigidez del castigo. El gobernador de la provincia de Cartagena en 1878 anotaba en su informe que "condenar a los individuos por muchos años a la inacción y silencio, a la privación del agua para baños generales, era lo mismo que condenarlo a una muerte lenta, a la desesperación y locura."34

Bajo esta nueva visión de la institución penitenciaria, el Estado Soberano de Bolívar, intentó cambiar el sentido de la función del penal, acorde con el programa político radical de masificar la educación primaria, introdujo en la penitenciaría del Estado, es decir, en la Casa de Prisión y Reclusión, los

${ }_{33}$ AHC. Gaceta de Bolívar. Domingo 23 de octubre de 1870 No. 117. pág. 426. ${ }^{34}$ AHC. Diario de Bolívar. 14 de agosto de $1878 . \mathrm{N}^{\circ} 1945$. pág. 1345. 
35 AHC. Gaceta de Bolívar. Cartagena. 21 de octubre de 1874. N ${ }_{36}^{\circ}$ AHC Diario de Bóg. 535. ${ }^{36}$ AHC. Diario de Bolívar. Cartagena, 17 de febrero de Sobre el orden disciplina en el siglo XIX colombiano, véase Safford, Frank (1985).

El ideal de lo práctico. Bogotá: Áncora Eds.

${ }_{3}$ B.B.C. Gaceta de Bolívar

25 de marzo de 1864.

${ }^{38}$ B.B.C. Diario de Bolívar, 6 de septiembre de 1879 . primeros intentos de educar e instruir al delincuente. En esta perspectiva, fue inaugurada en 1873 la Escuela Elemental de la Casa de Prisión y Reclusión, que pretendió educar a los reos para impartirles hábitos de disciplina y cambios en la moral, que permitiera a los penados ser útiles a la sociedad. Los progresos de la educación de esta escuela se medían mediante exámenes anuales ${ }^{35}$.

Como complemento al proceso educativo se implementaron políticas productivas dentro de las cárceles, es así como el 15 de enero de 1878 fue fundado el taller de sombrería, que representaba la posibilidad de rehabilitación del preso mediante el trabajo, asunto que le interesaba muchísimo a las élites gubernamentales, que veía en esto la posibilidad de contar con mano de obra barata para posibles proyectos productivos futuros ${ }^{36}$.

Pero a pesar de todas estas nuevas políticas de renovación de la vida penitenciaria, de la implementación de dispositivos disciplinadores de trabajo y estudio, la situación carcelaria seguía en crisis, es más, había empeorado, y la inseguridad y el hacinamiento seguían siendo la constante y el gran problema a solucionar dentro de todo este embarazoso panorama.

En el año de 1864 el Procurador General del Estado Soberano de Bolívar se había quejado en su informe de la situación carcelaria que padecía el Estado:

la sociedad no debe quedar abandonada a merced de los delincuentes que necesitan ser reprimidos en sus desordenes agresivos, para lo cual deben crearse establecimientos de castigo, hoi representados en nuestras cárceles inseguras, donde el reo condenado hoi, se puede fugar mañana, burlándose de la justicia para volver al teatro de sus crímenes detestables. ${ }^{37}$

Luego en el año de 1879, el Procurador General hablaba de la escandalosa cifra de 850 reos prófugos en todo el Estado ${ }^{38}$, lo que demostraba que pasados quince años la situación carcelaria en el Estado Soberano de Bolívar no había encontrado el camino de solución a su problemática y por el contrario, dicha situación había empeorado.

\section{Consideraciones finales}

Desde comienzos de la República la situación carcelaria era bastante crítica y fueron ingentes los esfuerzos por mejorar esta situación por parte del Estado. En esta perspectiva el Estado republicano creó un sistema penitenciario 
dependiente del poder ejecutivo y ligado al aparato judicial, en una estructura diseñada para atender las necesidades locales y regionales, constituyéndose el presidio como la institución de mayor importancia dentro de este esquema punitivo.

Luego en el nuevo orden federal, a cada Estado le correspondió organizar y administrar su aparato judicial y penitenciario; para lo cual contaba con toda la autonomía del caso. En este momento las condiciones de los pocos establecimientos de reclusión que existían en el país eran bastante precarias. La situación del Estado Soberano de Bolívar en este contexto no era la mejor, su situación era igualmente preocupante. Se hizo necesario entonces construir una nueva infraestructura penitenciaria y carcelaria acorde con las necesidades del Estado y conectarla con una nueva administración de justicia. Este proyecto debería estar soportado en una nueva legislación que permitiera el surgimiento de nuevas instituciones carcelarias claramente definidas y, lo más importante, que posibilitara el montaje real en términos físicos y financieros de una infraestructura penitenciaria segura y eficaz. Pero el verdadero problema fue la construcción de un aparato financiero eficiente que permitiera los recursos suficientes para poner en marcha este nuevo dispositivo penitenciario y así solucionar satisfactoriamente la demanda carcelaria que vivía el Estado Soberano de Bolívar.

A pesar de que se contó con fuentes diversas de financiación para satisfacer la demanda carcelaria, donde confluyeron recursos locales y regionales, incluyendo el esfuerzo económico de los vecinos, estos nunca se constituyeron en el músculo financiero eficaz que permitiera materializar la idea de la construcción de una infraestructura básica penitenciaria eficiente y al alcance de las necesidades del Estado, máxime cuando se apuntaba hacia un sistema carcelario más seguro y humano, en concordancia con lo que las ideas liberales planteaban al respecto.

En conclusión, lo que nunca pudieron lograr las autoridades gubernamentales del Estado Soberano de Bolívar, fue construir un mecanismo financiero que permitiera hacer viable un proyecto carcelario serio, seguro y eficaz, quedándose con las meras soluciones de paso que planteaba en su momento esta problemática. La realidad era apremiante y la situación no daba espera, por las críticas circunstancias que vivían los presos rematados en las cárceles y la inseguridad que planteaban los reos prófugos a las autoridades. En síntesis, este reto le quedó grande a las elites gubernamentales y este proyecto

Palubra No. 11. Septiembre de 2009 - Agosto de 2010 
reformista y ambicioso del nuevo esquema penitenciario liberal jamás se materializó en Bolívar y, todo lo contrario, se convirtió en uno de los grandes problemas administrativos del Estado, que nunca pudo resolver a su favor. Como se vio, en el año 1879, después de quince años de estar conviviendo con este problema el Procurador General hablaba de la escandalosa cifra de 850 reos prófugos en todo el Estado, lo que evidenciaba que la situación carcelaria en Bolívar había empeorado y que definitivamente, la política carcelaria y penitenciaria del Estado Soberano de Bolívar fue un rotundo fracaso.

\section{BIBLIOGRAFIA}

AGUIIERA, Mario. (2001). "La Administración de Justicia en el Siglo XIX." En: La Justicia en Colombia. Revista Credencial Historia. Edición 136. Abril. Bogotá.

CAMPUZANO CUARTAS, Rodrigo. (2000). "Sistema Carcelario en Antioquia Durante el Siglo XIX". En: Revista Historia y Sociedad, № 7, Medellín. págs. 87-123.

FOUCAULT, Michel. (2005). Vigilar y Castigar. El Nacimiento de la Prisión. Buenos Aires: Ed. Siglo XXI.

LÓPEZ DOMÍNGUEZ, Luis Horacio. (1990). Administraciones de Santander. Tomo II. Bogotá: Biblioteca Presidencia de la República.

MANTOVANI, Fernando. (1998). El Siglo XIX y las Ciencias Criminales. Bogotá: Editorial Temis.

MELOSSI, Darío y PAVARINI, Massimo. (1985). Cárcel y Fábrica, los Orígenes del Sistema Penitenciario. Siglos XVI-XIX. Bogotá: Editorial Siglo XXI.

NARANJO MESA, Vladimiro. (2003). Teoría Constitucional e Instituciones Políticas. Bogotá: Editorial Temis.

OCAMPO LÓPEZ, Javier. (1993). "José Ignacio de Márquez, El Civilista". En Revista Credencial Historia. Edición 45. Septiembre de 1993. Bogotá

PUERTA LEÓN, Heriberto. (2009). La Administración de Justicia en el Estado Soberano de Bolívar. Cartagena: Editorial Litocecopia.

SAFFORD, Frank. (1985). El ideal de lo práctico. Bogotá: Áncora Editores.

TOMÁS Y VALIENTE, Francisco. (1992). El Derecho Penal de la Monarquía Absoluta. Siglos XVI, XVII y XVIII. $2^{\circ}$ Ed. Madrid: Tecnos.

VILLEGAS DEL CASTILLO, Catalina. (2006). Del Hogar a los Juzgados: Reclamos Familiares en los Juzgados Superiores en el Tránsito de la Colonia a la Republica, 1800-1850. Bogotá: Ediciones Uniandes. 